\title{
SURFACE ROUGHNESS OF DIFFERENT GLASS IONOMER CEMENTS STORED IN DIFFERENT PH
}

\author{
Mohamed Riad Farid*, Eman Abu-Auf** and Dina Mounir El-Kady ${ }^{* * *}$
}

\begin{abstract}
Objective: The purpose of this study was designed to compare surface roughness of zinc containing glass ionomer to metal modified glass ionomer and the conventional glass ionomer cements, in vitro study. Influence of different $\mathrm{pH}$ on this parameter as well as effect of difference storage periods on the previous variables. Evaluation of new modified zinc glass ionomer (Chemfil rock) and choice of restoration in acidic consumption patients.
\end{abstract}

Material and methods: Three equal groups of 45 discs each. A zinc reinforced glass ionomer restoration (Chemfil rock), silver reinforced glass ionomer restoration (Ketac silver), and conventional glass ionomer restoration (Ketac fill). Surface roughness (Ra) was measured with USB digital surface profile gauge. Data were collected to correlate the (Ra) under the influence to variable $\mathrm{pH}$ solutions.

Results: It was found that Chem-Fil group recorded statistically significant $(\mathrm{P}<0.05)$ highest roughness mean value (237.63 Ra) followed by Ketac-Ag group (219.47 Ra) while Ketac-Fil group recorded statistically significant $(\mathrm{P}<0.05)$ lowest roughness mean value $(192.69 \mathrm{Ra})$ as indicated by multi-factorial ANOVA. Pair-wise Tukey's post-hoc tests showed non-significant $(\mathrm{p}>0.05)$ difference between Chem-Fil and Ketac-Ag groups

Conclusions: For different period of time, we concluded that all tested material do not improve (Ra) regardless the $\mathrm{Ph}$ of storage media.

KEYWORDS: Surface roughness, Glass ionomer, Ketac silver, Ketac fill.

\section{INTRODUCTION}

Glass ionomer cements (GICs) are widely used in dentistry because of a variety of beneficial properties; the two main reasons that have made GICs very popular are their permanent ionic bond to tooth structure, and their capacity to release fluoride, making them useful materials to replace dentin when used as bases in deep cavities ${ }^{[1]}$.

In order to improve mechanical properties, metal modified glass ionemer appeared in 1977

* Professor, Operative and Esthetics Dentistry Department Faculty of Oral and Dental Medicine, Cairo University ** Lecturer, Operative and Esthetics Dentistry Department Faculty of Oral and Dental Medicine, Cairo University *** Demonstrator, Operative and Esthetics Dentistry Department Faculty of Oral and Dental Medicine, Cairo University 
for the first time, by sintering the metal and glass powders together, strong bonding of the metal to the glass was achieved. However, their strength is still insufficient to replace amalgam alloys and their use should be confined to low stress - bearing cavity preparations ${ }^{[2]}$.

The manufacturer of a recently launched GIC (ChemFil Rock, Dentsply) followed a different approach to enhance material's stability, an enhanced setting reaction in the new GIC is supposed, due to the zinc content as part of its glass particles, leading thus to higher strength ${ }^{[3]}$.

One of the most important properties that determine the durability of restorative materials in the mouth is resistance to dissolution or disintegration. It has been known for a long time that acidic food and drinks may soften dental hard tissues ${ }^{[4]}$.

\section{MATERIALS AND METHODS:}

I.1.A zinc reinforced glass ionomer restoration (Chemfil rock)

I.2.A silver reinforced glass ionomer restoration (Ketac silver)

I.3.A conventional glass ionomer restoration (Ketac fill)

\section{Methods:}

A total of 150 specimens were used in the study and divided into three equal groups of 45 each according to the tested restorative materials. A specially designed teflon mold was used to preapare the specimens the molD was $2 \mathrm{~mm}$ thick and has a circular hole in its middle with an internal diameter $3 \mathrm{~mm}$. The Teflon mold was placed on a glass slab over a transparent polyester strip, and then the material was packed and the excess was removed using sharp \#12 bard barker scalpel blade. Another polyester strip and another glass slab were placed on the top of the mold, to ensure surface smoothness a constant $200 \mathrm{~g}$ load was applied ${ }^{[5]}$.
Each tested material was used according to manufacture instruction. Whereas;Chemfil material mixed at 4,300 rpm in Ivoclar Vivadent Silamat S5 amalgamator (U.S.A PATTERSON DENTAL) for $10 \mathrm{sec}$. The material was applied with the Aplicap Applier (3M ESPE, St Paul MN, USA), into the central hole of the Teflon mold and the excess was removed using sharp \#12 bard barker scalpel blade.

\section{Surface roughness test}

Surface roughness ( $\mathrm{Ra}$ ) was measured with USB digital surface profile gauge (figure 3 ), cut-off - 0.25 mm (Ecometer 224/2, Elcometer Instruments, Great Britain) and data were recorded using computer software (Elcomaster 2, Elcometer Instruments). The surface profile needle (radius of $2.5 \mu \mathrm{m}$ ) was positioned perpendicular over each test specimen performing five readings in different locations of the sample surface. After the five readings, the mean surface roughness values were obtained.

\section{Acidic challenge}

Each group of tested restorative material was divided into three equal subgroups of 15 , according to different immersion solution used in the study either water, Pepsi or orange juice, then each group was further divided into three equal subgroups of five each to the storage period; 24 hours; one week and one month at room temperature.

\section{Statistical Methods}

Data analysis was performed in several steps. Initially, descriptive statistics for each group results. Multi-factorial analysis of variance ANOVA test of significance comparing variables affecting mean values (GI cements, storage media and storage time). One way ANOVA followed by pair-wise Tukey's post-hoc tests were performed to detect significance between subgroups. Statistical analysis was performed using GraphPad Prism4 statistics software for Windows. $\mathrm{P}$ values $\leq 0.05$ were considered to be statistically significant in all tests. 


\section{RESULTS}

\section{Roughness values (Ra)}

Descriptive statistics of roughness values ( $\mathrm{Ra}$ ) showing mean values and standard deviation for GI cements as function of storage media and storage time are summarized in table (1) and graphically drawn in figure (1).

\section{DISCUSSION}

This study aimed to examine the surface roughness and microhardness of several glass ionomers based restorative materials under the influence of exposure to variable $\mathrm{pH}$ solutions. The setting reaction of glass ionmer is a an acid base reaction resulting in the formation of calcium polycarboxylate salt in initially set cement. After

TABLE (1) Descriptive statistics of Roughness results (Mean values \pm SDs) for GI cements as function of storage media and storage time

\begin{tabular}{|c|c|c|c|c|c|c|c|c|c|}
\hline \multirow{5}{*}{} & \multicolumn{3}{|c|}{ Chem-Fil } & \multicolumn{3}{c|}{ Ketac-Fil } & \multicolumn{3}{c|}{ Ketac-Ag } \\
\cline { 2 - 10 } & Day & Week & Month & Day & Week & Month & Day & Week & Month \\
\hline \multirow{4}{*}{ Orange } & 316.33 & $263.08 \pm$ & 168.67 & 196.08 & 151.61 & 124.29 & 270.29 & 271.21 & 177.13 \\
& \pm 15.8 & 63.8 & \pm 56.1 & \pm 42.3 & \pm 44.9 & \pm 38.9 & \pm 26.6 & \pm 56.5 & \pm 57.7 \\
\hline \multirow{3}{*}{ Pepsi } & 216.5 & 286.1 & 201.31 & 274.67 & 166.42 & 177 & 226.92 & 354 & 220.71 \\
& \pm 61.6 & \pm 28.5 & \pm 9.12 & \pm 40.6 & \pm 19.7 & \pm 36.2 & \pm 28.7 & \pm 72.2 & \pm 41.1 \\
\hline \multirow{3}{*}{ Water } & 187.22 & 216.46 & 283 & 186 & 241.61 & 216.58 & 98.94 & 189.13 & 166.92 \\
& \pm 58.7 & \pm 63.5 & \pm 23.9 & \pm 40.1 & \pm 32.7 & \pm 10.4 & \pm 11.3 & \pm 21.6 & \pm 45.1 \\
\hline
\end{tabular}

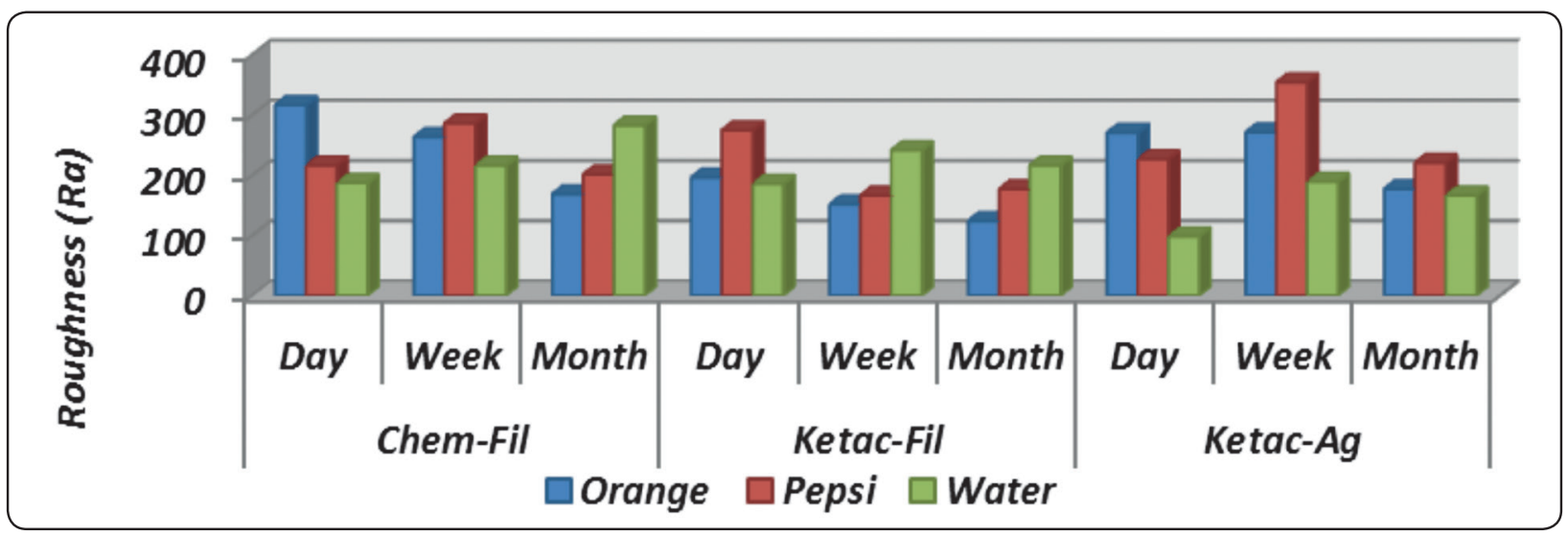

Fig. (1) Histogram of Roughness mean values for GI cements as function of storage media and storage time. 
cement maturation the aluminum polycarboxylate salt and the final set cement is formed of both partially reacted and unreacted particles embedded in the calcium and aluminum polycarboxylate salts $^{[6]}$.

One of the most frequent challenges that face glass ionomer restoration is the acidity. The glass ionomer restoration are based on acid/base reaction ,during exposure to low $\mathrm{pH}$, the hydrogen ion attack the metal cation in the restoration leading to dissolution of glass ionomer cement which affect many of its properties like hardness and surface roughness ${ }^{[4]}$. For this reasons, in this study Pepsi and orange juice a two acidic solution with different $\mathrm{pH}$ were selected to evaluate its effect on surface roughness of glass ionomer restoration. The higher the surface roughness, the higher the plaque accumulation which increases the acidity and increase risk of caries. Increasing acidity will cause more dissolution of material and more surface roughness ${ }^{[7]}$. This is with agreement with the result of this study which show the least surface roughness with water of least $\mathrm{pH}$ while Pepsi and orange with higher ph show the higher surface roughness. This could be explained by that upon the hydrolysis of glass ionomer the hydrogen ion attack the matrix causing the leach out of calcium and aluminum ion which are responsible for the cross linking of polycarboxlic molecules together. Once this free metal atom reach the surface they are released into the surrounding media leaving pores within the glass ionomer leading to its break down.

Also the results of this study show that the higher surface roughness is at one week followed by one day then one month which is in agreement with the result of ( Dalia et al., 2012) ${ }^{[8]}$ and in disagreement with (Bala et al., 2010) ${ }^{[7]}$. This can be explained by the fact that the dissolution of glass ionomer usually take three phases (1) surface wash-off, (2) diffusion from the solid state, and (3) surface corrosion ${ }^{[9]}$.The surface layer of glass ionomer is formed o cement matrix when the water diffuse to it, it cause its swelling with the formation subsurface pores. Once the surface layer is degraded it exposes the unreacted and partially reacted cement powder, pores and filler particle which lead to increased surface roughness. By the continuous attack of acid and water the filler particle will be debonded and unreacted particles will be degraded leaving a smoother surface ${ }^{[10,11]}$.

The study show that the chem fill rock has the highest surface roughness followed by ketac silver and ketac fill. The result are in agreement with (Zoergiebel and ellie, 2013) ${ }^{[3]}$, in disagreement with (Al Angari et al., 2013) ${ }^{[12]}$, this can be explained by the distribution of filler, its size and type ${ }^{[7]}$.

\section{CONCLUSION}

Therefore under the circumstances of this study the following conclusions could be derived:

- The highest surface roughness was that of of Chemfil rock followed by that of Ketac silver, but Ketac silver show the lowest microhradness value followed by that of Chemil fil rock. Ketac fill show the highest microhardness and lowest surface roughness value.

- The acidic $\mathrm{pH}$ affects both surface roughness and michrohardness of all tested material. The composition and type of acid play a role in its effect on materials.

- Increasing time of storage increase the effect of $\mathrm{pH}$ on the surface roughness and microhardness of the tested materials.

\section{REFERENCES:}

1. Mazzaoui SA, Burrow MF and Tyas MJ. Fluoride release from glass ionomer cements and resin composites coated with a dentin adhesive. Dental Materials 2000;16:166-171.

2. Nagaraja Upadhya P, and G. Kishore. Glass Ionomer Cement - The Different Generations. Trends Biomater Artif Organs 2005;18:158-165. 
3. Zoergiebel JI and Nicoleta. Evaluation of a conventional glass ionomer cement with new zinc formulation: effect of coating, aging and storage agents. Clinical oral investigations 2013;17:619-626.

4. Hamouda IM. Effects of various beverages on hardness, roughness, and solubility of esthetic restorative materials. Journal of Esthetic and Restorative Dentistry 2011; 23:315-322.

5. Wang XY and Yap AUJ. Effects of environmental calcium and phosphate on wear and strength of glass ionomers exposed to acidic conditions. Journal of Biomedical Materials Research Part B: Applied Biomaterials 2009; 88:458-464.

6. Kakaboura A. Aging of glass-ionomer cements. Dental materials in vivo, aging and related phenomena Quintessence, Carol Stream, Illinois 2002:79-98.

7. Bala O, Arisu HD, Yikilgan I, Arslan S and Gullu A. Evaluation of surface roughness and hardness of different glass ionomer cements. European journal of dentistry $2010 ; 6 ; 79$.
8. Dalia YI, Zaki EM, Aly H and Mohamed AA. Effect of Simulated Gastric Juice on Surface Characteristics of Direct Esthetic Restorations. Australian Journal of Basic and Applied Sciences 2012;6:686-694.

9. Kuhn AT and Wilson AD. The dissolution mechanisms of silicate and glass-ionomer dental cements. Biomaterials 1985; 6:378-382.

10. Matsuya SM, YamamotoY, Yamane Y and Masaji. Erosion process of a glass ionomer cement in organic acids. Dent Mater J 1984;3:210-219.

11. Kantovitz KR, Pascon FM, Correr GM, Alonso RCB, Rodriguess LKA, and Alves MC. Influence of environmental conditions on properties of ionomeric and resin sealant materials. Journal of Applied Oral Science 2009;17:294-300.

12. Al-Angari S, Hara AT, Chu T-M, Platt J, Eckert G, and Cook NB. Physicomechanical properties of a zincreinforced glass ionomer restorative material. Journal of Oral Science 2014;56:11-16. 